\title{
FAIL TO RETRIEVE GALLSTONES IN LAPAROSCOPIC CHOLECYSTECTOMY- A STUDY
}

\author{
Purujit Choudhury 1
}

${ }^{1}$ Associate Professor, Department of Surgery, Gauhati Medical College, Assam.

ABSTRACT
BACKGROUND
Gallstone spillage during laparoscopic cholecystectomy is not uncommon and despite all precautions and adoption of safety
measures spilt gallstone remain unretrieved. We are trying to document the incidence of spilt gallstones during laparoscopic
cholecystectomy, the cause and consequences of such spillage, probable measure to be adopted to prevent gallstone spillage during
laparoscopic cholecystectomy and to take care to retrieve all spilt stones.

\section{MATERIALS AND METHODS}

The study included 150 consecutive laparoscopic cholecystectomy pardoned between October 2014 and November 2015. Data were collected in a prospective manner. Detail study was conducted in terms of diagnosis and consequences of spillage of gallstones. Followup were performed at the end of 1 week, 1 month, 6 months and 1 year.

\section{RESULTS}

The spillage of gall stones during surgery occurred in $19.04 \%$ of the cases. Majority of the spillage occurred due to perforation of the gall bladder during dissection followed by application of toothed grasper. Although, all visible spilt stones were retrieved during surgery, complication rate of $0.66 \%$ was observed.

\section{CONCLUSION}

The incidence and complications secondary to the spillage of gall stones during standard laparoscopic cholecystectomy is low, but avoidable; various complications can occur over a large period of time. Thus, it is advisable to retrieve as many gallstones as possible, short of converting to a laparotomy.

\section{KEYWORDS}

Laparoscopic Cholecystectomy; Gall Stone Spillage; Unretrieved Intraperitoneal Gallstones.

HOW TO CITE THIS ARTICLE: Choudhury P. Fail to retrieve gallstones in laparoscopic cholecystectomy- a study. J. Evolution Med. Dent. Sci. 2017;6(71):5035-5039, DOI: 10.14260/Jemds/2017/1095

\begin{tabular}{|c|c|}
\hline BACKGROUND & This incidence increases by greater than two-fold when \\
\hline $\begin{array}{l}\text { Laparoscopic cholecystectomy (LC) has been the gold } \\
\text { standard for symptomatic gallstones for last } 30 \text { years. It is } \\
\text { said to be the standard procedure for acute cholecystitis too. } \\
\text { Overtime, the rate of common bile duct injuries from LC has } \\
\text { declined. Unfortunately, the incidence of spillage of gallstones } \\
\text { has remained unchanged. Gallbladder perforation with stone } \\
\text { spillage into the peritoneal cavity is more frequent with }\end{array}$ & $\begin{array}{l}\text { the stones are unretrieved. }{ }^{[3]} \text { In an inexperienced hand, } \\
\text { chances of gallstones spillage increases during } \\
\text { cholecystectomy in acute cholecystitis. Oedematous gall } \\
\text { bladder wall-liver interface is equally a potential area of } \\
\text { dissection through which gall bladder perforation and stone } \\
\text { spillage is not uncommon during removal of gall bladder from } \\
\text { liver bed in acute oedematous cholecystitis. }\end{array}$ \\
\hline
\end{tabular}
laparoscopic cholecystectomy as compared with open cholecystectomy. Early reports on laparoscopic cholecystectomy stated that stones left in the peritoneal cavity had no deleterious effect.[1] Although the incidence of spilt gallstones and their complications are low, they are of large variety.[2] Thus, it makes a significant problem. The variety of complications are caused by lost gallstones [3-5]; may range from simple surgical site infection to more serious forms like broncholithiasis. The incidence of complications related to spillage of gallstones during laparoscopic cholecystectomy is between $2.3 \%$ and $7 \%$.

Financial or Other, Competing Interest: None.

Submission 31-07-2017, Peer Review 23-08-2017,

Acceptance 29-08-2017, Published 04-09-2017.

Corresponding Author:

Dr. Purujit Choudhury,

P. O. Gopinath Nagar,

Arya Path,

Gauhati-781016, Assam.

E-mail:drpurujit@yahoo.in

DOI: $10.14260 /$ jemds $/ 2017 / 1095$

\section{Aims and Objectives}

- To document the incidence of gallstone spillage during laparoscopic cholecystectomy.

- To document the causes of gallstones spillage.

- To document the consequences of spilt gallstones.

\section{MATERIALS AND METHODS}

The study includes 150 consecutive cases of laparoscopic cholecystectomy performed between October 2014 and November 2015. The surgeries were performed by author and under supervision. A prospective collection of data was obtained in accordance with the proforma, which documented patient's detailed diagnosis, preoperative physical and ultrasound abdomen findings, intraoperative details such as technique, spillage of stones, cause for spillage, method and port of extraction of specimen, duration of surgery and postoperative events and complications were documented. 
Size of GB- 88 (normal), 58 (distended), 1 (contracted) Presence of sludge- 15

Number of stones- 2 (none), 10 (single), 135 (multiple) GB wall thickness- $29(>3 \mathrm{~mm})$ CBD size- $15(>7 \mathrm{~mm})$

Size of Stone- 141 (mobile), 6 (impacted)

Size of Stone- $130(<10 \mathrm{~mm}), \quad 4(1-20 \mathrm{~mm}), 13(>2 \mathrm{~cm})$ Table 1. Ultrasound Findings

The follow-up was performed at the end of 1 week, 1 month, 6 months and 1-year postoperative. The reviews at 1 week were in the outpatient department, at 1 month some were outpatient visits, rest being telephonic interviews and the remaining follow-up at 6 months and 1 year was performed by telephonic interviews. Data collected were analysed for incidence of spillage of gallstones and complications related to such events during laparoscopic cholecystectomy.

\section{RESULTS}

Our study included 150 consecutive laparoscopic cholecystectomy patients between October 2014 and November 2015. Of these, 92 patients were female and the remaining 58 patients were male. The average age of the study group was 48 years. Of these 150 patients, 3 patients underwent conversion to open cholecystectomy due to the following-

- Extensive dense adhesions in 2 cases.

- Obliterated Calot with acute oedematous in 1 case.

Thus, it accounts for a conversion rate of $2 \%$. Majority of the patients came with complaints of pain in the right upper quadrant and/or epigastric region. Second most frequently encountered complaint was that of nonspecific dyspepsia. A total of 39 patients had diabetes mellitus.

Of the total study group 78\% patients had uncomplicated symptomatic gallstones, $3.33 \%$ accounted for incidentally detected asymptomatic gallstones, $0.66 \%$ had gallbladder polyps, $16.66 \%$ accounted for gallstone complications (such as gallstone pancreatitis, cholecystitis, obstructive jaundice, Mirizzi's syndrome, mucocele and empyema gallbladder) and $1.33 \%$ had acalculous cholecystitis. Table 1 represents the pre-operative ultrasound findings. In this table, the cut-off for normal thickness of gallbladder wall was taken as $<3 \mathrm{~mm}$ and that for common bile duct as $<7 \mathrm{~mm}$. Increased wall thickness implied inflammation. A dilated common bile duct implicated either a stone, a stricture in the distal CBD or a passed stone. Majority of the patients exhibited multiple gallstones of $<1 \mathrm{~cm}$ and mobile. The duration of surgery was noted to be between 30 and 60 mins. in $87.75 \%$ cases. Adhesions of varying degrees were noted in $71.8 \%$ cases leading to conversion of $1.33 \%$. Minimal bleeding was noted in $51.35 \%$ cases and moderate bleeding was noted in $37.16 \%$ cases, while no bleeding was noted in $10.2 \%$ cases. Gallstone spillage occurred in $19.04 \%$ cases. In $67.85 \%$ of these cases, three to five stones were spilt. In $32.14 \%$ cases, less than two stones were spilt and in $7.14 \%$ cases more than five stones were spilt. Peritoneal toileting was done in $53.74 \%$ cases. All visible peritoneal stones were completely retrieved. Details of the intraoperative findings are shown in Table 2. Table 3 represents mechanism for spillage of gall stones. It was apparent that gallbladder perforation led to spillage in all cases. The most common case for gallbladder perforation was dissection followed by the application of tooth grasper to the gallbladder. The least traumatic method was application of no tooth grasper to the gallbladder. Table 4 delineates the postoperative events and observations noted during followup. Prior to discharge, two patients developed collections in the gallbladder fossa-

1. Haematoma secondary to slipped cystic artery clip, which was corrected following a relook surgery.

2. A biliary leak from the cystic duct stump with loculated collection was encountered in another patient who was managed conservatively.

\begin{tabular}{|l|c|}
\hline 1. Surgery duration & $\begin{array}{c}6<30 \text { mins; } 129=30-60 \text { mins; } \\
12=60-90 \text { mins; } 2>90 \text { mins. }\end{array}$ \\
\hline $\begin{array}{l}\text { 2. Extension of } \\
\text { incision }\end{array}$ & 4 \\
\hline 3. Spilt stones & 28 \\
\hline 4. Wash given & $59<250 \mathrm{~mL}$ \\
\hline 5. Bleeding & $\begin{array}{c}15 \text { none; } 76 \text { minimal; } 55 \\
\text { moderate; } 1 \text { severe }\end{array}$ \\
\hline 6. Port of extraction & 91 (umbilicus); 56 (epigastrium) \\
\hline 7. Adhesion & 88- partial; 12- complete; 7- dense \\
\hline \multicolumn{2}{|c|}{ Table 2. Intraoperative Findings } \\
\hline \multicolumn{2}{|c}{}
\end{tabular}

\begin{tabular}{|c|}
\hline Tooth grasper- 21 \\
\hline Non-toothed grasper- 2 \\
\hline During traction- 15 \\
\hline During dissection (blunt and sharp dissection)- 33 \\
\hline Table 3. Mechanism for Spillage \\
\hline
\end{tabular}

At 1 week of postoperative followup, one patient complained of pain and discharge at the umbilical port site. On removal of the suture, wound dehiscence was noted. Further exploration of wound on OPD basis revealed a gallstone in the subcutaneous plain. Another patient was readmitted for pancreatitis and found to have CBD sludge on investigations, which was managed by endoscopic retrograde cholangiopancreatography.

In our study, we observed a complication rate of $2.66 \%$ for laparoscopic cholecystectomy; however, complication rate from spilt gallstones was $0.66 \%$. The world literature has documented complication rates for spilt gallstones to range between $1.3 \%$ and $2.3 \%$ for retrieved stones and as high as $7 \%$ for unretrieved stones. No complaints related to the surgery were observed at 1, 6 and 12 months of postoperative followup. In our study, 5 patients were lost for followup, of which 3 patients had documented spillage of gallstones.

\section{DISCUSSION}

Cholecystectomy has evolved from open to laparoscopic approach over the past decade, ${ }^{[6]}$ laparoscopy being the current gold standard for treating gallstone disease. One of the issues that have come up in the recent years with laparoscopic cholecystectomy is the unchanged incidence of 


\begin{tabular}{|c|c|c|c|c|c|}
\hline Parameters & $\begin{array}{c}\text { While in } \\
\text { Hospital }\end{array}$ & $\begin{array}{c}\text { 1 week } \\
\text { Post- op }\end{array}$ & $\begin{array}{c}\text { 1 month } \\
\text { Post-op }\end{array}$ & $\begin{array}{c}\text { 6 months } \\
\text { Post-op }\end{array}$ & $\begin{array}{c}\text { 1 yr. } \\
\text { Post-op }\end{array}$ \\
\hline Fever & 7 & 0 & 0 & 0 & 0 \\
\hline Pain abdomen & 33 & 2 & 0 & 0 & 0 \\
\hline $\begin{array}{c}\text { Refd pain to Rt } \\
\text { shoulder }\end{array}$ & 10 & 0 & - & - & - \\
\hline Post-op WBC & 2 & 1 & 0 & 0 & 0 \\
\hline $\begin{array}{c}\text { Post-op } \\
\text { Ultrasound }\end{array}$ & 3 & 1 & 0 & 0 & 0 \\
\hline Abnormal US & 2 & 1 & 0 & 0 & 0 \\
\hline $\begin{array}{c}\text { Average days } \\
\text { in hospital }\end{array}$ & 2.51 & - & - & - & - \\
\hline $\begin{array}{c}\text { Discharge/ } \\
\text { sinus }\end{array}$ & 0 & 1 & 0 & 0 & 0 \\
\hline $\begin{array}{c}\text { Intestinal } \\
\text { obstruction }\end{array}$ & 0 & 0 & 0 & 0 & 0 \\
\hline $\begin{array}{c}\text { Lost for } \\
\text { followup }\end{array}$ & 0 & 0 & 4 & 5 & 5 \\
\hline \multicolumn{2}{|c|}{ Table 4. Post-Operative Details as Inpatient } \\
\hline
\end{tabular}

\begin{tabular}{|c|c|c|}
\hline Parameters & Our Study & International Data \\
\hline Spillage of stones & $18.91 \%$ & $2 \%-11 \%$ \\
\hline $\begin{array}{c}\text { Complication } \\
\text { related to spilt of } \\
\text { GS }\end{array}$ & $.66 \%$ & $\begin{array}{c}2.3 \% \text { for retrieved stones } \\
\text { and } 7 \% \text { for unretrieved }\end{array}$ \\
\hline GB perforation & $18.26 \%$ & $11.6 \%-20 \%$ \\
\hline $\begin{array}{c}\text { Unretrieved } \\
\text { intraperitoneal } \\
\text { stones }\end{array}$ & 0 & $2.4 \%-4 \%$ \\
\hline Followup & 12 months & 44.8 months \\
\hline Table 5. Comparison between Our Study and \\
International Data
\end{tabular}

Bile and gallstone spillage into the abdominal cavity. ${ }^{[7,8]}$ The reason for this includes limited space for dissection, issues with instrumentation that causes laceration of the gallbladder wall and the tendency to deal with acute friable gallbladders, as the experience of surgeons for this procedure has increased. The fate of spilt gallstones ${ }^{[9,10,11]}$ is not clearly known. In the earlier era of laparoscopic cholecystectomy, it was recommended that spilt gallstones are harmless and can be left alone.[12,13] Earlier reports by Clinic in the beginning of the era of laparoscopic cholecystectomy claim no deleterious effect from spilt gallstones left in the peritoneal cavity through rat models.[12] Similar conclusions were drawn by Welch with animal models.[13]

However, as data accrued, several complications ${ }^{[14,15]}$ were reported. Brickman's study published in 2002 included 116 papers derived from a Medline search looked into a total of 91 cases of gallstone complications following laparoscopic cholecystectomy over a period of 8 years. They concluded that gallbladder perforation and stone spillage might cause hazardous complications, and in case of loss of numerous or large pigmented stones conversion to open surgery may be justified.[16]

Some of these complications are not so significant, while some others are very significant which include abscess in the abdominal wall, broncholithiasis, stone expectoration, cellulitis, dyspareunia, erosion to the back, fat necrosis

posterior of the rectus muscle, fever, fistula formation, gallstone granuloma, gluteal abscess, granulomatous peritonitis mimicking endometriosis, ileus, intestinal obstruction, implantation malignancy, incarcerated hernia, intra-abdominal abscess, jaundice, liver abscess mimicking malignancy, middle colic artery thrombosis, mimicking acute appendicitis, paracolic abscess, paraumbilical tumour, peritoneal abscess formation, pelvic abscess, pelvic stones, peritonitis, pleural empyema, fluid collections, pneumonia, port site stones, port site abscess, recurrent staphylococcal bacteraemia, retrohepatic abscess, retroperitoneal abscess, retroperitoneal actinomycosis, right flank abscess, small bowel obstruction, stones in gastrocolic omentum, stones in hernia sac, stones of the ovary, stones in the fallopian tube, subhepatic abscess, subphrenic abscess, thoracoabdominal mycosis, transdiaphragmatic abscess, umbilical wound abscess and vesicle granuloma.[3,4,16,17] In this prospective study, we have documented the late complication of spilt stones in our institution. The incidence of spilt gallstones was noted to be $18.91 \%$ in our series. ${ }^{[18,19]}$ In the literature, the incidence ranges between $2 \%$ and $11 \% .^{[5]}$

The reason for our incidence being higher is likely to be the policy of taking on all gallbladder disease irrespective to the state of acuteness and friability of the gallbladder. The reported incidence of unretrieved ${ }^{[20,21,22]}$ gallstones is $0 \%$ in our series, while an attempt was made to take out all the spilt stones[23] diligently. It is difficult to claim no stones were left behind. Data suggest an incidence of $2.4 \%-4 \%{ }^{[13,24,25]}$ The incidence of complication from retained stones in our series is very low at $0.66 \%$. The literature suggests $2.3 \%$ for retrieved stones and 7\% for unretrieved stones.[26] These data were produced by Woodsfield who included six studies, covering 18,280 laparoscopic cholecystectomy cases. The low incidence in our study is likely to be a fortuitous occurrence. Also, in our study the number is limited and the follow-up is of short duration compared to other series with an average follow-up of 44.8 months. [27] Thus, it can be said that there is a significant incidence of spilt gallstones during laparoscopic cholecystectomy, particularly when cases are not selective. While our study showed a small complication rate, the recommendation is that every attempt must be made to extract all spilt stones. However, this process entails damage to the surrounding structures, the occasional gallstone may be left behind. In such a case, it is important to document it. It is important to note that spillage itself should be prevented to the extent possible.

\section{The Operative Steps suggested to Prevent Spillage are as Follows-}

- $\quad$ Careful dissection.[27,28]

- Making sure not to cause gallbladder perforation. [29-35]

- Suctioning out gallbladder content prior to starting dissection in a fully distended turgid gallbladder.

- Use of appropriate instruments such as non-toothed graspers.

- Diligent application of clips to close the cystic duct wall.

- Liberal use of irrigation and Endobags to avoid port site complications.[33] 
Table 5 shows a comparison between observations of our study and those of international data.

\section{CONCLUSION}

Incidence and complications secondary to the spillage of gallstones and bile during standard laparoscopic cholecystectomy are low and avoidable. When spillage occurs, removal of the stones and peritoneal toileting is the key step to avoid complications. In our study, complications due to spilt and unretrieved gallstones account for $0.66 \%$ of all the cases, which is much lower than described in available datas. As noted by International data, the rates of complications range are around $2.3 \%$ for retrieved intraperitoneal gallstones and $7 \%$ for unretrieved gallstones. ${ }^{[26]}$ It is therefore advisable to retrieve as many gallstones as possible during LC, short of converting to a laparotomy.[24-34]

\section{REFERENCES}

[1] Welch NT, Hinder RA, Ciurej T, et al. Laparoscopic capture of "escaped" gallstones. Surg Lap Endosc 1991;1(1):42-4.

[2] Zehetner J, Shamiyeh A, Wayand W. Lost gallstones in laparoscopic cholecystcctomy: all possible complications. Am J Surg 2007;193(1):73-8.

[3] Diez J, Arozamena C, Gutierrez L, et al. Lost stones during laparoscopic cholecystectomy. HPB Surg 1998;11(2):105-9.

[4] Johnston S, O`Malley K, McEntee G, et al. The need to retrieve the dropped stone during laparoscopic cholecystectomy. Am J Surg 1994;167(6):608-10.

[5] Memon MA, Deeik RK, Maffi TR, et al. The outcome of unretrieved gallstones in the peritoneal cavity during laparoscopic cholecystectomy. A prospective analysis. Surg Endosc 1999;13(9):848-57.

[6] De U. Evolution of cholecystectomy: a tribute to Carl August Langenbuch. Indian J Surg 2004;66:97-100.

[7] Alcayir 1, Yerdel MA, Kubasioglu U. Clinicopathological outcome of intra peritoneal retained gallstones with different characteristics. H P B Surgery 1995;5:95.

[8] Wetscher G, Schwab G, Feud F, et al. Subcutaneous abscess due to gallstones lost during laparoscopic cholecystectomy. Endosc 1994;26(3):324-5.

[9] Catarci M, Zaraca F, Scaccia M, et al. Lost intraperitoneal stones after laparoscopic cholecystectomy: harmless sequel or reason for reoperation? Surg Lap Endoc 1993;3(4):318-22.

[10] Dittrich K, Weiss H. Lleus of the small intestine caused by a lost gallstone! a late complication of laparoscopic cholecystectomy. Chirurg 1995;66(4):443-5.

[11] Guy PR, Watkin DS, Thompson MH. Late discharge of stones after laparoscopic cholecystectomy. Br J Surg 1993;80(8):1052.

[12] Cline RW, Poulos E, Clifford EJ. An assessment of potential complications cause by intraperitoneal gallstones. Am Surg 1994;60(5):303-5.

[13] Welch N, Llintler RA, Fitzgibbons RJ. Gallstones in the peritoneal cavity. A clinical and experimental study. Surg Lap Endosc 1991;1(4):246-7.
[14] Castellon-Pavon CJ, Morales-Artero S, MartínezPozuelo A, et al. Complications due to spilled gallstones and surgical clips during laparoscopic cholecystectomy. Cir Esp 2008;84(1):3-9.

[15] Soper NJ, Dunnegan DL. Does intra operative gallbladder perforation influence the early outcome of laparoscopic cholecystectomy? Surg Laparoscope Endosc 1991;1(3):156-61.

[16] Brockmann JG, Kochcr T, Senninger NJ, et al. Complications due to gallstones lost during laparoscopic cholecystectomy. Surg Endosc 2002;16(8):1226-32.

[17] Dasari BV, Loan W, Carey DP. Spilled gallstones mimicking peritoneal metastases. JSLS 2009;13(1):736.

[18] Gooneratne DL. A rare late complication of spilled gallstones. N Z Med J 2010;123(1318):62-6.

[19] Pappas AV, Lagoudianakis EE, Keramidaris D, et al. The last place you would expect to find a gallstone. JSLS 2011;15(2):248-51.

[20] Karabulut N, Tavasli B, Kiroglu Y. Intra-abdominal spilled gallstones simulating peritoneal metastasis: CT and MR imaging features (2008: 1b). Eur Radiol 2008;18(4):851-4.

[21] Irkorucu 0, Tascilar 0 , Emre AU, et al. Missed gallstones in the bile duct and abdominal cavity: a case report. Clinics (Sao Paulo) 2008;63(4):56l-4.

[22] Hussain Ml, Al-Akeely MH, Alam MK, et al. Abdominal wall abscess following laparoscopic cholccystectomy: an unusual late complication of lost gallstones. J Coll Physicians Surg Pak 2010;20(11):763-5.

[23] Arishi AR, Rabie ME, Khan MS, et al. Spilled gallstones: the source an enigma. JSLS 2008;12(3):321-5.

[24] Wilton PB, Andy OJ, Peters JJ, et al. Laparoscopic cholecystectomy. Leave no (spilled) stone unturned. Surg Endosc 1993;7(6):537-8.

[25] Targarona EM, Balague C, Cifuentes A, et al. The spilled stone. A potential danger after laparoscopic cholecystectomy. Surg Endosc 1995;9(7):768-73.

[26] Woodfield JC, Rodgers M, Windsor JA. Peritoneal gallstones following laparoscopic cholecystectomy: incidence, complications and management. Surg Endosc 2004;18(8):1200-7.

[27] Daradkeh SS, Suwan Z, Abu-Khalaf M. Preoperative ultrasonography and prediction of technical difficulties during laparoscopic cholecystectomy. World J Surg 1998;22(1):75-7.

[28] Cacdac RG, Lakra YP. Abdominal wall sinus tract secondary to gallstones: a complication of laparoscopic cholecystectomy. J Lap Surg 1993;3(5):509-11.

[29] Cuschieri A, Dubois F, Mouiel J, et al. The European experience with laparoscopic cholecystectomy. Am J Surg 1991;161(3):385-7.

[30] Sarli L, Pietra N, Costi R, et al. Gallbladder perforation during laparoscopic cholecystectomy. World J Surg 1999;23(11):1186-90.

[31] Jones DB, Dunnegan DL, Soper NJ. The influence of intraoperative gallbladder perforation on long-term outcome after laparoscopic cholecystectomy. Surg Endosc 1995;9(9):977-80. 
[32] Assaff Y, Matter L, Sabo E, et al. Laparoscopic cholecystectomy for acute cholecystitis and the consequence of gallbladder perforation, bile spillage, and "loss" of stones. Eur J Surg 1998;164(6):425-31.

[33] Hui TT, Giurgiu DL, Margulies DR, et al. Latrogenic gallbladder perforation during laparoscopic cholecystectomy: etiology and sequelae. Am Surg 1999;65(10):944-8.
[34] Leslie KA, Rankin RN, Duff JH. Lost gallstones during laparoscopic cholecystectomy: are they really benign? Can J Surg 1994;37(3):240-2.

[35] Kent RB, Stahl RD. Laparoscopic retrieval of spilled stones. Surg Lap Endosc 1992;2(2):152-3. 